\title{
Low Doses of Fentanyl Block Central Sensitization in the Rat Spinal Cord In Vivo
}

Justus Benrath, M.D., " Christina Brechtel,† Eike Martin, M.D., Ph.D., $\ddagger$ Jürgen Sandkühler, M.D., Ph.D.§

Background: $\mu$-Opioid receptor agonists are strong analgesics. However, their usefulness for preemptive analgesia is controversial. The authors tested antinociceptive and preemptive properties of fentanyl as a $\mu$-opioid receptor agonist in a model of spinal nociception in vivo.

Methods: C fiber-evoked potentials were recorded in the superficial laminae I-II of the rat lumbar spinal cord with glass microelectrodes in response to electrical stimulation of the sciatic nerve. High-frequency stimulation was applied on the sciatic nerve to induce long-term potentiation of $C$ fiber-evoked field potentials, a form of central sensitization. To test the effect of fentanyl on acute nociception, fentanyl was infused intravenously at increasing doses $\left(6-192 \mu \mathrm{g} \cdot \mathrm{kg}^{-1} \cdot \mathrm{h}^{-1}\right)$. One hour after start of infusion, high-frequency stimulation was applied to evaluate effects of fentanyl on the induction of long-term potentiation.

Results: In the absence of fentanyl, high-frequency stimulation potentiated $\mathrm{C}$ fiber-evoked field potentials to $149 \pm 12 \%$ of controls (mean \pm SEM; $n=6$ ) for at least $1 \mathrm{~h}$. Increasing doses of fentanyl led to a significant reduction of $\mathrm{C}$ fiberevoked potentials in a dose-dependent manner. The induction of long-term potentiation was blocked by low doses of fentanyl (infusion 12-48 $\mu \mathrm{g} \cdot \mathrm{kg}^{-1} \cdot \mathrm{h}^{-1}$ ). At high doses, fentanyl did not block the induction of long-term potentiation (infusion 96-192 $\left.\mu \mathrm{g} \cdot \mathrm{kg}^{-1} \cdot \mathrm{h}^{-1}\right)$.

Conclusions: Low doses of fentanyl block the synaptic form of central sensitization in the rat spinal cord in vivo, but higher doses do not have this effect.

CHRONIC pain after surgery has been a major problem because $20 \%$ of patients attending chronic pain clinics implicated surgery as one of the causes of their chronic pain and, in approximately half of these cases, surgery was the sole cause. ${ }^{1}$ Surgical damage is able to induce hyperalgesia (abnormal intense pain elicited by noxious stimulation) and allodynia (pain induced by normally nonpainful stimuli). These enhanced responses to noxious or nonnoxious stimuli result from peripheral ${ }^{2}$ or central sensitization. ${ }^{3-5}$ The sensitization of peripheral nociceptors is typically limited in time to the period of primary injury. Central sensitization may, however, out-

\footnotetext{
* Resident, † Ph.D. Student, $\ddagger$ Professor and Chairman, Klinik für Anaesthesiologie, Universität Heidelberg. \ Professor, Institut für Hirnforschung, Universität Wien, Wien, Austria.

Received from the Klinik für Anaesthesiologie, Universität Heidelberg, Heidelberg, Germany. Submitted for publication April 29, 2002. Accepted for publication January 8, 2004. Supported by the Pain Research Program of the Medical Faculty of the University of Heidelberg, Heidelberg, Germany; grant No. Sa 435/10-2 from the Deutsche Forschungsgemeinschaft, Bonn, Germany; and institutional sources of the Klinik für Anaesthesiologie, University of Heidelberg, Heidelberg, Germany. Presented at the 30th Annual Meeting of the Society for Neuroscience, New Orleans, Louisiana, November 4-9, 2000, and the 31st Annual Meeting of the Society for Neuroscience, San Diego, California, November $10-15,2001$. Dr. Benrath and Ms. Brechtel contributed equally to the article.

Address correspondence to Dr. Benrath: Klinik für Anästhesie und Allgemeine Intensivmedizin B, Universität Wien, Währinger Gürtel 18-20, AKH, A-1090 Wien, Austria. Address electronic mail to: justus.benrath@univie.ac.at. Individual article reprints may be purchased through the Journal Web site, www.anesthesiology.org.
}

last the period of noxious input to the central nervous system by hours to weeks, and in some patients, the period of abnormal pain sensitivity may last even longer. Recent evidence suggests that synaptic long-term potentiation (LTP) can be specifically induced at synapses between C-fiber afferents and neurons in superficial spinal dorsal horn that mediate hyperalgesia. ${ }^{6}$ This is considered a cellular mechanism of central sensitization and hyperalgesia (see Sandkühler ${ }^{4}$ for review). LTP can be induced in the spinal cord by peripheral trauma, inflammation, or nerve injury. LTP of synaptic strength in nociceptive pathways may aggravate postoperative hyperalgesia and allodynia but may also lead to phantom pain and chronic postsurgical pain. ${ }^{1}$ Although postoperative pain and chronicity of surgical pain are of enormous clinical importance, the mechanisms of the induction and the prevention of LTP are not fully understood.

Calcium influx into spinal cord neurons is required for LTP induction. Strong excitation of dorsal horn neurons is essential for calcium influx through voltage-gated calcium channels and voltage- and ligand-gated glutamatergic receptors of the $N$-methyl-D-aspartate (NMDA) subtype. Consequently, activity-dependent calcium influx can be reduced by any means that prevents strong excitation of nociceptive spinal dorsal horn neurons, e.g., by agonists at $\mu$-opioid receptors (MORs). Opioid agonists were shown to inhibit voltage-gated $\mathrm{Ca}^{2+}$ currents in neurons ${ }^{7}$ and to reduce excitation by presynaptic and postsynaptic inhibition. ${ }^{8}$ Therefore, blockade opioid receptors could be clinically important to prevent LTP induction and thereby spinal sensitization in patients. In our investigation, we tested the clinically used MOR agonist fentanyl on its ability to influence the induction and maintenance of LTP.

\section{Methods}

\section{Animals}

After obtaining approval from the Institutional Animal Care Committee (Regierungspräsidium Karlsruhe, Germany), the experiments were performed on male Sprague-Dawley rats weighing 250-320 g (Charles River Deutschland, Sulzfeld, Germany). Animals were kept under temperature-controlled environmental conditions on a 12:12 h light:dark cycle and were fed a standard diet (Altromin C 1000; Altromin, Lage, Germany) with access to food and water ad libitum.

\section{Preparation of the Animals}

To establish LTP under different anesthetics, halothane (3.5 vol\% inspiratory) in two thirds $\mathrm{N}_{2} \mathrm{O}$ and one third $\mathrm{O}_{2}$ 
was used to induce and urethane was used $(1.2 \mathrm{~g} / \mathrm{kg}$ intravenous) to maintain anesthesia, or isoflurane in two thirds $\mathrm{N}_{2} \mathrm{O}$ and one third $\mathrm{O}_{2}$ was used to induce (3.5 vol\% inspiratory) and maintain (1.0 vol\% expiratory) anesthesia, or sevoflurane in two thirds $\mathrm{N}_{2} \mathrm{O}$ and one third $\mathrm{O}_{2}$ was used to induce ( $6 \mathrm{vol} \%$ inspiratory) and to maintain (1.7 vol\% inspiratory) anesthesia. Halothane in two thirds $\mathrm{N}_{2} \mathrm{O}$ and one third $\mathrm{O}_{2}$ was used to induce and urethane was used to maintain anesthesia in all experiments in which fentanyl was used. Concentrations of inhalational anesthetics were monitored with a gas analyser (Capnomac Ultima; DatexOhmeda, Duisburg, Germany). The surgical level of anesthesia was verified by stable arterial blood pressure and constant heart rate during noxious stimulation of the interdigital area of the paw.

A polyethylene catheter (Portex Ltd., Hythe, Kent, United Kingdom) was inserted into the right femoral vein for application of drugs and for constant infusion of $0.9 \%$ normal saline and $0.1 \%$ sodium bicarbonate. The right femoral artery was cannulated with a polyethylene catheter and was continuously infused by a heparin solution $(2.5 \mathrm{IE} / \mathrm{ml})$ to monitor arterial blood pressure and heart rate (Plugsys; Hugo Sachs, March, Germany). Mean arterial blood pressure and heart rate were continuously recorded with a pen recorder (L 120E; Linseis, Selb, Germany). The trachea was intubated with a 14gauge intravenous cannula to allow mechanical ventilation. Muscle relaxation was achieved with $1 \mu \mathrm{g} \cdot \mathrm{kg}^{-1}$. $\mathrm{h}^{-1}$ pancuronium bromide. Atropin $(0.05 \mathrm{mg} / \mathrm{kg})$ was given once at the beginning of the preparation to reduce tracheal secretion. Glucose $(5 \%, 10 \mathrm{ml} / \mathrm{kg})$ was injected subcutaneously for nutrition of the animals during the 8-12 h of experimental procedure. Blood gas analyses were performed at regular intervals during the experiment (Rapidlap 348; Bayer Diagnostics, Fernwald, Germany), and ventilation parameters were adapted if necessary. Body temperature was kept constant between $37^{\circ}$ and $38^{\circ} \mathrm{C}$ by means of a feedback-controlled heating blanket.

Lumbar segments L4 and L5 of the spinal cord were exposed by laminectomy, and the dura mater was incised longitudinally. All exposed tissue was covered with warm agar (1.6\%) except the recording segments of the spinal cord column.

The left sciatic nerve was dissected free for bipolar electrical stimulation with a silver hook electrode. This electrode was separated from the surrounding muscles by a sheet of elastic plastic film (Parafilm, Chicago, IL). All exposed nervous tissues were then covered with warm paraffin oil.

\section{Electrophysiologic Recordings and Nerve Stimulation}

In response to electrical stimulation of the sciatic nerve, field potentials were recorded with glass microelectrodes (3-5 M $\Omega$ ) 300-600 $\mu \mathrm{m}$ from the dorsal sur- face of the spinal cord dorsal horn (laminae I and II). Microelectrodes were pulled on a Flaming/Brown micropipette puller (Sutter Instrument Co., Novato, CA) and moved into the spinal cord by an electronically controlled microstepper. Recordings were made with an ISO-DAM-amplifier (World Precision Instruments Inc., Sarasota, FL). Corner frequencies of the band-pass filter were set to $1 \mathrm{kHz}$ and $0.1 \mathrm{~Hz}$, respectively. The signal output was monitored on a digital oscilloscope (Hameg HM 250, Oceanside, CA) and digitized at a sampling rate of $5 \mathrm{kHz}$ by an A/D-converter card (DT281-F-16SE). Data were stored in a personal computer for off-line analysis. Test stimuli $(10-25 \mathrm{~V}, 0.5 \mathrm{~ms})$ were applied at intervals of $5 \mathrm{~min}$ to the sciatic nerve. For induction of LTP, high-frequency stimulation (HFS) consisting of four trains of $100-\mathrm{Hz}, 40-$ to $50-\mathrm{V}, 0.5-\mathrm{ms}$ pulses for $1 \mathrm{~s}$ at $10-\mathrm{s}$ intervals was applied. The distance between the stimulation site at the sciatic nerve and the recording site in the lumbar spinal dorsal horn was $8 \mathrm{~cm}$.

\section{Drug Administration}

Fentanyl, atropin, $8.4 \%$ sodium hydrogen carbonate, naloxone, and pancuronium were given intravenously. Heparin was given intraarterially, and 5\% glucose was injected subcutaneously. All stock solutions were diluted in $0.9 \%$ saline. Volumes for intravenous injection were $200 \mu \mathrm{l}$. The total continuous injection volume per hour (intravenous plus intraarterial) was $0.8 \%$ per body weight.

\section{Experimental Procedures}

Test stimuli $(10-25 \mathrm{~V}, 0.5 \mathrm{~ms})$ were applied to the sciatic nerve for $60 \mathrm{~min}$ at intervals of $5 \mathrm{~min}$. The following experimental protocols were performed:

1. To establish LTP under different anesthetics $(n=13$ urethane; $\mathrm{n}=26$ isoflurane; $\mathrm{n}=7$ sevoflurane), test stimuli were given to achieve baseline recordings for $60 \mathrm{~min}$ as mentioned above. Then, the conditioning HFS was applied to the sciatic nerve, and responses to test stimuli were recorded for another $60 \mathrm{~min}$.

2. To test the effect of the MOR agonist fentanyl on the magnitude of $\mathrm{C}$ fiber-evoked potentials (acute nociception), increasing doses of fentanyl were given intravenously, which in all cases consisted of a bolus followed by an infusion. Baseline recordings were performed for $60 \mathrm{~min}$ as mentioned above. Then, the bolus was given, and the infusion was started. Recordings were continued for another $60 \mathrm{~min}$. The following dose regimens (one per animal) were used:

- fentanyl bolus of $5 \mu \mathrm{g} / \mathrm{kg}$ followed by fentanyl infusion of $6 \mu \mathrm{g} \cdot \mathrm{kg}^{-1} \cdot \mathrm{h}^{-1}(\mathrm{n}=7)$

- fentanyl bolus of $10 \mu \mathrm{g} / \mathrm{kg}$ followed by fentanyl infusion of $12 \mu \mathrm{g} \cdot \mathrm{kg}^{-1} \cdot \mathrm{h}^{-1}(\mathrm{n}=7)$

- fentanyl bolus of $20 \mu \mathrm{g} / \mathrm{kg}$ followed by fentanyl infusion of $24 \mu \mathrm{g} \cdot \mathrm{kg}^{-1} \cdot \mathrm{h}^{-1}(\mathrm{n}=5)$ 
- fentanyl bolus of $40 \mu \mathrm{g} / \mathrm{kg}$ followed by fentanyl infusion of $48 \mu \mathrm{g} \cdot \mathrm{kg}^{-1} \cdot \mathrm{h}^{-1}(\mathrm{n}=5)$

- fentanyl bolus of $40 \mu \mathrm{g} / \mathrm{kg}$ followed by fentanyl infusion of $96 \mu \mathrm{g} \cdot \mathrm{kg}^{-1} \cdot \mathrm{h}^{-1}(\mathrm{n}=5)$

- fentanyl bolus of $40 \mu \mathrm{g} / \mathrm{kg}$ followed by fentanyl infusion of $192 \mu \mathrm{g} \cdot \mathrm{kg}^{-1} \cdot \mathrm{h}^{-1}(\mathrm{n}=6)$

- bolus injections of $200 \mu \mathrm{l}$ saline followed by saline infusion of $0.2 \mathrm{ml} / \mathrm{h}$ to serve as control $(\mathrm{n}=6)$

3. To test the effect of these different doses of fentanyl on the induction of LTP (preemptive effect), HFS was applied to the sciatic nerve under the above-mentioned running fentanyl infusions. After HFS, fentanyl infusions were continued for another $60 \mathrm{~min}$, during which responses of test stimuli were recorded.

4. Naloxone was used as the opioid receptor antagonist to test whether the effect of fentanyl on C fiber-evoked potentials depends on the opioid receptor. Baseline recordings were performed for $60 \mathrm{~min}$, and then a fentanyl bolus of $40 \mu \mathrm{g} / \mathrm{kg}$ was applied, which was followed by a fentanyl infusion of $96 \mu \mathrm{g} \cdot \mathrm{kg}^{-1} \cdot \mathrm{h}^{-1}$ for $120 \mathrm{~min}$. Then, $100 \mu \mathrm{g} / \mathrm{kg}$ naloxone was given intravenously three times in 15-min intervals, and recordings were continued for another $60 \mathrm{~min}(\mathrm{n}=3)$.

Data Analysis and Statistics. The area under the curve of the $\mathrm{C}$ fiber-evoked field potentials was determined off-line by parameter extraction, which was implemented by the software Experimenter's Workbench (DataWave Technologies, Longmont, CO). The area of the $\mathrm{C}$ fiber-evoked field potentials was determined as the integral of the waveform. Measurements were normalized for each rat such that the mean of the respective baseline values was equal to 100 . Changes of $\mathrm{C}$ fiberevoked potentials on acute nociception were characterized by post minus baseline differences (values 30-60 min before start of fentanyl infusion minus values 30-60 min after start of fentanyl infusion). These changes within each dose were compared with the change in the zero dose using analysis of variance and post hoc tests according to Dunnett. This procedure controls the type I error for comparisons of all doses to the zero dose within each experiment. The grand mean and its corresponding 95\% confidence interval (CI) were estimated to test whether there was an effect of fentanyl on $\mathrm{C}$ fiberevoked potentials or of HFS on C fiber-evoked potentials under fentanyl infusion.

The same model was applied to test the changes after application of HFS during fentanyl infusion. Changes of C fiber-evoked potentials in experiments in which HFS was given during fentanyl infusion were characterized by postcomparison minus precomparison (values 30-60 min before HFS compared with values 30-60 min after application of HFS). In addition, the corresponding 95\% CIs were defined for each dose respectively. Calculations were performed using the SAS software system version 8.2 (SAS Institute Inc., Cary, NC). A significant difference was considered when $P$ was less than 0.05 . All values are expressed as mean $\pm \mathrm{SEM}$.

\section{Results}

Recording of C Fiber-evoked Potentials and LTP of $C$ Fiber-evoked Potentials under Inhalational Anesthesia

$\mathrm{A} \beta$ and $\mathrm{C}$ fiber- evoked field potentials could clearly be distinguished after stimulation of the sciatic nerve (fig. 1A, inset). C fiber-evoked field potentials that were characterized by a negative focus in superficial spinal dorsal horn, long latencies (90-120 ms, corresponding to conduction velocities $<1.2 \mathrm{~m} / \mathrm{s}$ ), and high thresholds $(10-25 \mathrm{~V})$ were investigated further.

High-frequency stimulation consistently induced LTP in urethane-anesthetized rats to $149 \pm 12 \%$ of control $(n=13)$, in isoflurane-anesthetized rats to $152 \pm 6 \%$ of control ( $\mathrm{n}=26)$, and in sevoflurane-anesthetized rats to $132 \pm 6 \%$ of control $(n=7)$ (figs. $1 \mathrm{~A}-\mathrm{C}$ ).

$\mathrm{C}$ fiber-evoked potentials remained unchanged when isoflurane was increased for $20 \mathrm{~min}$ from 1 vol\% inspiratory to 2 vol\% inspiratory and decreased back to 1 vol\% inspiratory in four animals (data not shown).

\section{Fentanyl Decreases C Fiber-evoked Potentials}

The MOR agonist fentanyl reduced $C$ fiber-evoked potentials in a dose-dependent manner: At its lowest dose (bolus $5 \mu \mathrm{g} / \mathrm{kg}$, infusion $6 \mu \mathrm{g} \cdot \mathrm{kg}^{-1} \cdot \mathrm{h}^{-1}, \mathrm{n}=7$ ), fentanyl had no effect on $\mathrm{C}$ fiber- evoked potentials (fig. $2 \mathrm{~A}$ ). Increasing doses of fentanyl led to significant reductions of $\mathrm{C}$ fiber-evoked potentials (figs. $2 \mathrm{~B}-\mathrm{F}$ and fig. 3). At its highest dose (bolus $40 \mu \mathrm{g} / \mathrm{kg}$, infusion $192 \mu \mathrm{g}$. $\mathrm{kg}^{-1} \cdot \mathrm{h}^{-1}, \mathrm{n}=6$ ), fentanyl reduced responses to $20 \%$ of control $60 \mathrm{~min}$ after the start of the fentanyl injection regimen (fig. 2F).

The reduction due to fentanyl was fully reversible. Naloxone $(100 \mu \mathrm{g} / \mathrm{kg})$ that was given $2 \mathrm{~h}$ after the start of the fentanyl infusion (bolus $40 \mu \mathrm{g} / \mathrm{kg}$, infusion $96 \mu \mathrm{g} \cdot \mathrm{kg}^{-1} \cdot \mathrm{h}^{-1}, \mathrm{n}=3$ ) completely antagonized the reduction in $\mathrm{C}$ fiber-evoked potentials by fentanyl (data not shown).

\section{Differential Effects of Increasing Doses of Fentanyl on LTP Induction}

One hour after the beginning of fentanyl infusion regimens, HFS was applied to the sciatic nerve to investigate the effect of fentanyl on the induction of LTP. There was a significant overall (intercept) increase of the C fiberevoked potentials of $26.5 \%$ (95\% CI: 16.8, 36.1). The mean changes of the separate doses were as follows:

- saline infusion ( $\mathrm{n}=6)$ : mean change, 50.7 (95\% CI: $25.7,75.7)$

- fentanyl infusion of $6 \mu \mathrm{g} \cdot \mathrm{kg}^{-1} \cdot \mathrm{h}^{-1}(\mathrm{n}=7)$ : mean change, 33.3 (95\% CI: 10.2, 56.5) 

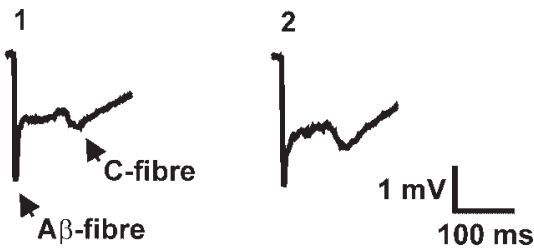

A Urethane
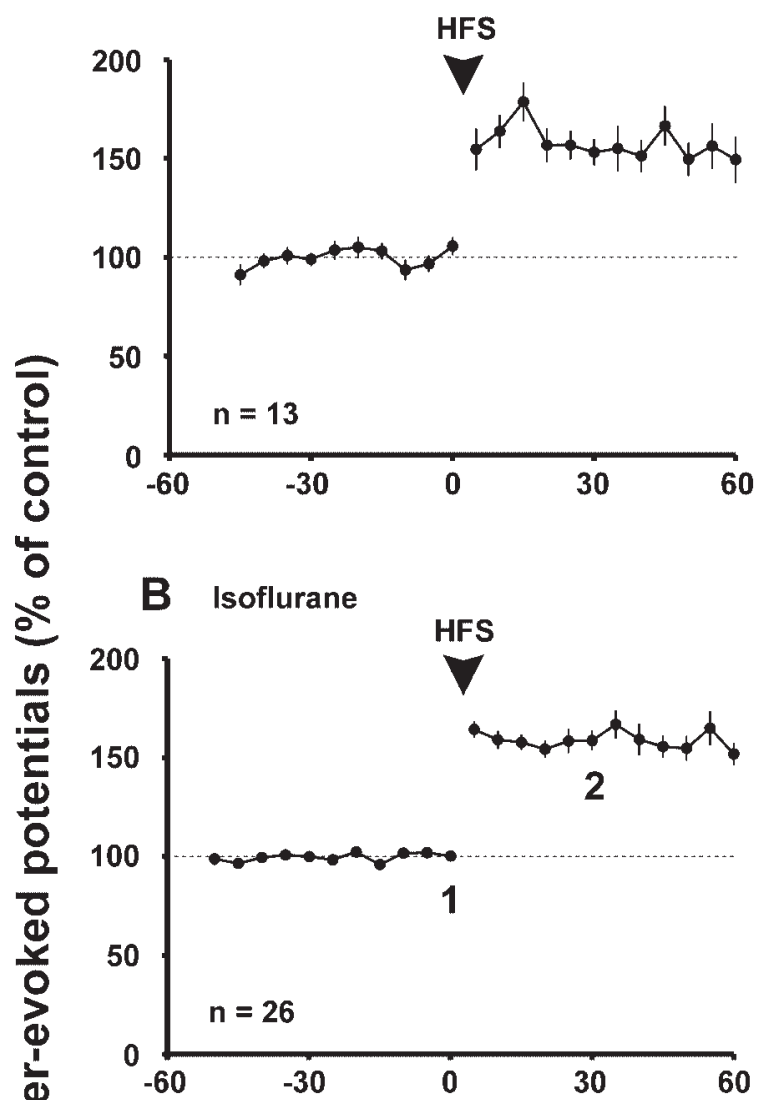

C Sevoflurane

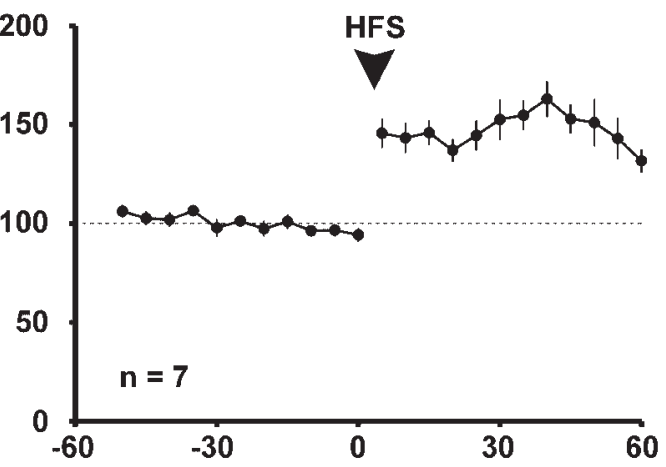

Time (min)

- fentanyl infusion of $12 \mu \mathrm{g} \cdot \mathrm{kg}^{-1} \cdot \mathrm{h}^{-1}(\mathrm{n}=7)$ : mean change, 7.4 (95\% CI: $-15.8,30.5)$

- fentanyl infusion of $24 \mu \mathrm{g} \cdot \mathrm{kg}^{-1} \cdot \mathrm{h}^{-1}(\mathrm{n}=5)$ : mean change, 11.4 (95\% CI: $-16,38.8)$
Fig. 1. Induction of long-term potentiation of synaptic strength between primary afferent $C$ fibers and neurons in superficial spinal dorsal horn by high-frequency stimulation (HFS) of sciatic nerve fibers at $\mathrm{C}$-fiber strength. In each experiment, $\mathrm{C}$ fiber-evoked potentials were provoked by electrical stimulation of the sciatic nerve. Responses were normalized to the area of $\mathrm{C}$ fiber-evoked potentials recorded $60 \mathrm{~min}$ before HFS was applied. Mean areas \pm SEMs were expressed as percent of controls and were plotted versus time. HFS resulted in long-term potentiation during urethane anesthesia, isoflurane, and sevoflurane. Original recordings from field potentials immediately before and $30 \mathrm{~min}$ after HFS during isoflurane anesthesia are shown above the graphs. ${ }^{1,2}$

- fentanyl infusion of $48 \mu \mathrm{g} \cdot \mathrm{kg}^{-1} \cdot \mathrm{h}^{-1}(\mathrm{n}=5)$ : mean change, 28.3 (95\% CI: 1, 55.7)

- fentanyl infusion of $96 \mu \mathrm{g} \cdot \mathrm{kg}^{-1} \cdot \mathrm{h}^{-1}(\mathrm{n}=5)$ : mean change, 35.3 (95\% CI: 8, 62.8)

- fentanyl infusion of $192 \mu \mathrm{g} \cdot \mathrm{kg}^{-1} \cdot \mathrm{h}^{-1}(\mathrm{n}=6)$ : mean change, 18.8 (95\% CI: 6, 43.8)

A CI that overlaps 0 reveals a significant difference, and a CI that does not overlap 0 reveals no significant difference. Therefore, the lowest dose of fentanyl (bolus $5 \mu \mathrm{g} / \mathrm{kg}$, infusion $6 \mu \mathrm{g} \cdot \mathrm{kg}^{-1} \cdot \mathrm{h}^{-1}, \mathrm{n}=7$ ), which revealed no effect on $\mathrm{C}$ fiber-evoked potentials, also failed to block the induction of LTP (fig. 3). The next higher dosages of fentanyl used (bolus $10 \mu \mathrm{g} / \mathrm{kg}$, infusion $12 \mu \mathrm{g} \cdot \mathrm{kg}^{-1} \cdot \mathrm{h}^{-1}, \mathrm{n}=7$, and bolus $20 \mu \mathrm{g} / \mathrm{kg}$, infusion $24 \mu \mathrm{g} \cdot \mathrm{kg}^{-1} \cdot \mathrm{h}^{-1}, \mathrm{n}=5$ ) blocked the induction of LTP (fig. 3). Even higher fentanyl dosages (bolus $40 \mu \mathrm{g} / \mathrm{kg}$, infusion $48-192 \mu \mathrm{g} \cdot \mathrm{kg}^{-1} \cdot \mathrm{h}^{-1}, \mathrm{n}=5$ or $\mathrm{n}=6$, respectively) failed to block the induction of LTP (fig. 3). Although these high doses of fentanyl did not block the induction of LTP, the potentiated C fiberevoked potentials all clearly remained below the control values before the start of fentanyl infusion (figs. 2D-F and fig. 3).

\section{Discussion}

The main result of this study is a U-shaped doseresponse relation of the MOR agonist fentanyl on the induction of synaptic LTP in nociceptive pathways. At a very low dose, fentanyl was not able to block $C$ fiberevoked field potentials or prevent the induction of LTP of synaptic strength on C fibers. At intermediate doses, fentanyl blocked C fiber-evoked responses and LTP induction. At the highest doses tested, fentanyl showed an increasing antinociceptive effect but did not block the induction of LTP.

\section{Induction of LTP under Different Anesthetics}

In our experiments, surgical levels of anesthesia by volatile anesthetic isoflurane in combination with nitrous oxide failed to prevent synaptic LTP in nociceptive pathways, a form of central sensitization. There is dis- 
Fig. 2. Effects of increasing doses of fentanyl on the $C$ fiber-evoked field potentials and on the induction of long-term potentiation. One hour after the start of fentanyl infusion, high-frequency stimulation (HFS) was given. Responses were normalized to the area of $C$ fiber-evoked potentials recorded $60 \mathrm{~min}$ before HFS was applied. Mean responses \pm SEMs were expressed as percent of controls and were plotted versus time.

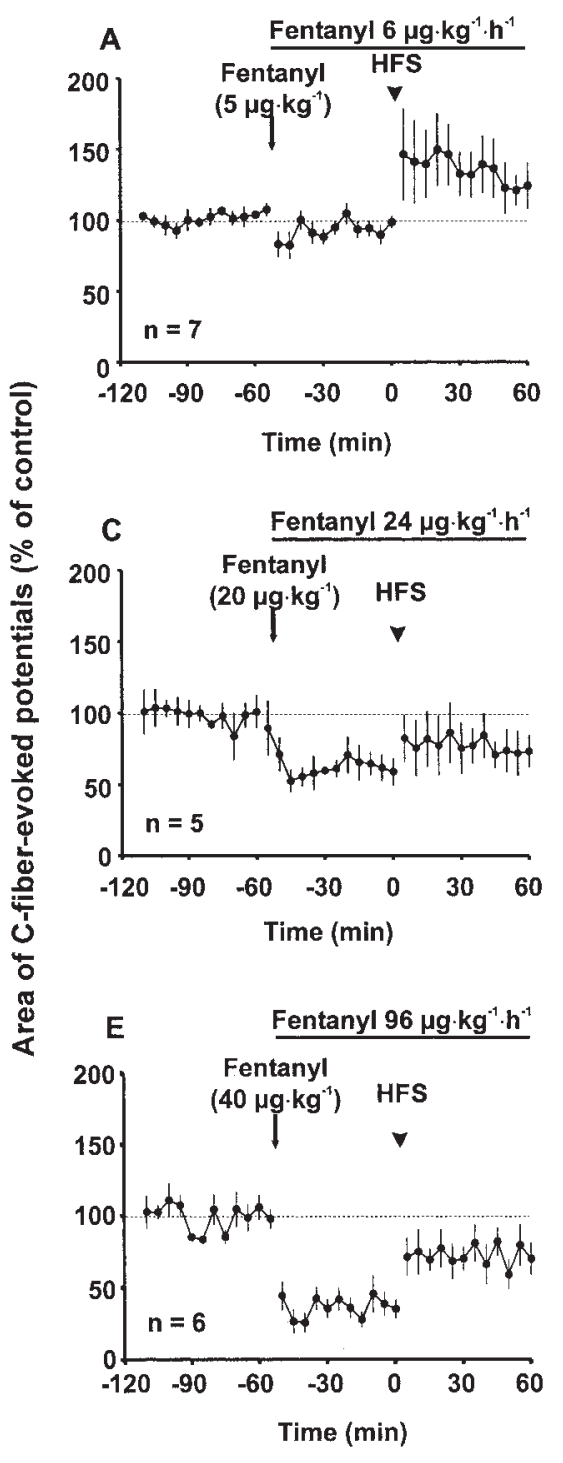

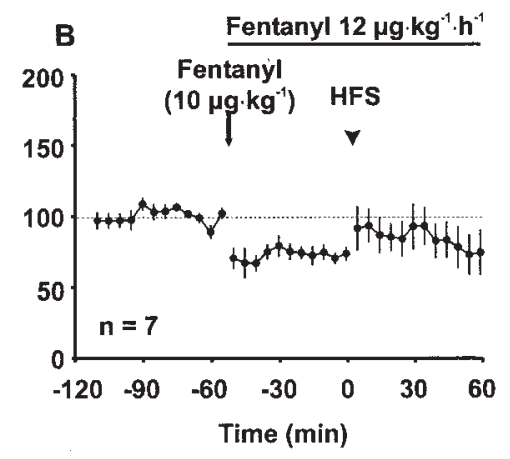
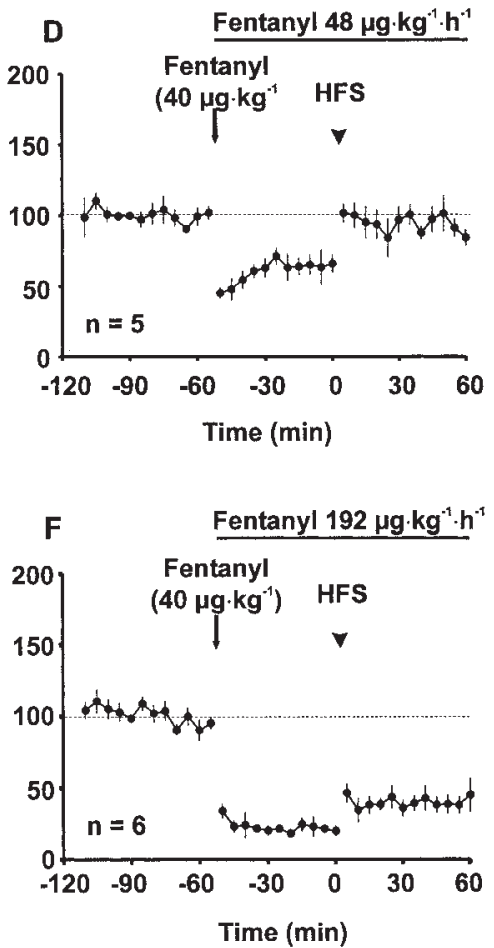

cussion about the exact mechanisms of action of volatile anesthetics. Suppression of neuronal electrical activity by volatile anesthetics has been ascribed to interactions with the A type of the $\gamma$-aminobutyric acid $\left(\mathrm{GABA}_{\mathrm{A}}\right)$ receptor and glycine receptors. ${ }^{9}$ After binding of GABA to the $\mathrm{GABA}_{\mathrm{A}}$ receptor, the channel opens to allow chloride ions to diffuse across the postsynaptic membrane. Volatile anesthetics prolong channel opening of $\mathrm{GABA}_{\mathrm{A}}$ and glycine receptors and consequently increase postsynaptic inhibition. ${ }^{9}$ Isoflurane blocks the induction of LTP in the hippocampus in vitro ${ }^{10}$ and suppresses somatosensory information transfer to the thalamic level in vivo by enhancing thalamic $\mathrm{GABA}_{\mathrm{A}}$ receptor-mediated inhibition. ${ }^{11}$ The major action of volatile anesthetics seems to be supraspinal because isoflurane has a variable and minimal depressant effect on dorsal horn cell responses to noxious mechanical stimulation. ${ }^{12}$ In our experiments, an increase of isoflurane concentration from 1 to 2 vol\% did not influence nociceptive synaptic transmission in the spinal dorsal horn. Furthermore, nei- ther isoflurane nor sevoflurane nor nitrous oxide prevented the induction of LTP. Nitrous oxide may have some potency as an NMDA receptor antagonist, ${ }^{13}$ but in our experiments, nitrous oxide at the concentration used did not prevent the induction of LTP, which requires the activation of NMDA receptors. ${ }^{14,15}$

\section{Differential Effects of Fentanyl on the Induction of LTP}

The activation of opioid receptors results in at least three actions on synaptic transmission: presynaptic inhibition of $\mathrm{Ca}^{2+}$ channels, postsynaptically inhibition of adenylyl cyclase, and membrane hyperpolarization via activation of $\mathrm{K}^{+}$channels (see Ingram $^{8}$ for review). These mechanisms may synergistically act to reduce the C fiber-evoked potentials by fentanyl in the current study. None of the doses of fentanyl tested blocked the input onto the dorsal horn neurons completely. This is in accord with studies that have shown that opioids reduce but do not abolish noxious evoked 


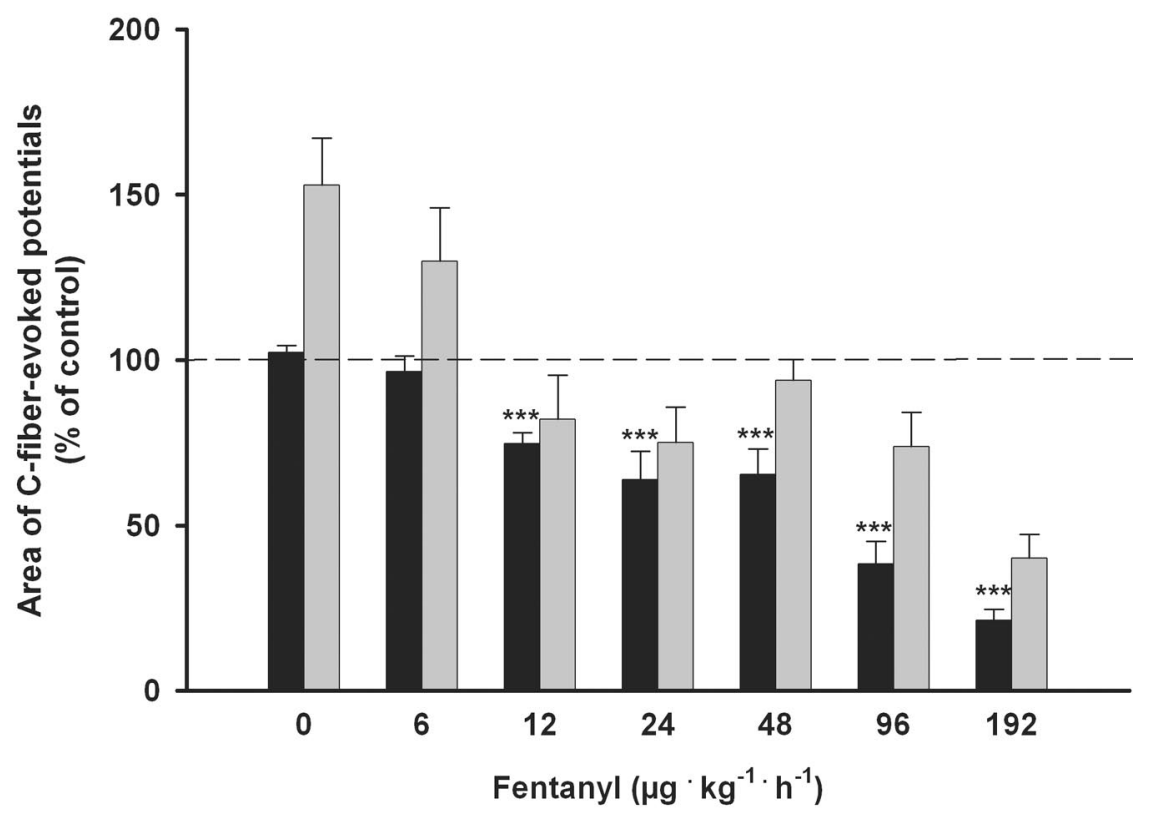

Fig. 3. Dose-dependent reduction of $\mathrm{C}$ fiber-evoked potentials by fentanyl (black bars). Bars shows means of $\mathrm{C}$ fiberevoked potentials \pm SEMs ${ }^{* * *} P<0.001$; values 30-60 min before start of fentanyl infusion regimen $v s$. values $30-60 \mathrm{~min}$ after start of infusion regimen; $n=5-7$ ). Gray bars show mean C fiber-evoked potentials 30-60 min after high-frequency stimulation (values $30-60 \mathrm{~min}$ before high-frequency stimulation during fentanyl infusion $v s$. values $30-60 \mathrm{~min}$ after high-frequency stimulation during fentanyl infusion; $\mathbf{n}=5-7 ; c f$. fig. 2 ). release of substance $\mathrm{P}^{16,17}$ and glutamate $\mathrm{e}^{18}$ in the dorsal horn of the spinal cord.

At the lowest dose used, fentanyl revealed neither antinociceptive nor preemptive action. Higher doses of fentanyl, however, significantly depressed C fiberevoked potentials, proving their potent antinociceptive action. This confirms the spinal action of opioids in animal models of nociception ${ }^{19-21}$ and provides a synaptic mechanism of action as strong analgesics in the clinical situation.

The induction of LTP was fully blocked during the infusion of doses of fentanyl that were not fully antinociceptive. This suggests that fentanyl is more potent to block central sensitization than nociception. Because LTP induction requires release of glutamate and activation of postsynaptic NMDA receptor, the presynaptic and postsynaptic inhibition by fentanyl well explains block of LTP induction. Our results are in line with an in vitro study that shows that the MOR agonist DAMGO inhibited NMDA receptor-dependent LTP in spinal cord slices of neonatal rats. ${ }^{22}$

However, at higher doses, fentanyl did not prevent LTP induction. This phenomenon may be explained by the interactions between postsynaptic NMDA receptor and postsynaptic opioid receptors. ${ }^{23}$ Fentanyl may lead to enhanced NMDA receptor-mediated currents in trigeminal dorsal horn neurons ${ }^{24}$ and in nucleus accumbens neurons. ${ }^{25}$ In both studies, the enhancement of NMDA currents by $\mu$ opioids was mediated by protein kinase $C$, an intracellular enzyme that can be activated by intracellular $\mathrm{Ca}^{2+}$ or phospholipase $\mathrm{C}$ pathway. ${ }^{24,25} \mathrm{Ac}-$ tivation of protein kinase $\mathrm{C}$ reduces the $\mathrm{Mg}^{2+}$ block of NMDA receptor and thereby considerably facilitates currents through NMDA receptor. ${ }^{26}$ Removal or significant reduction of voltage-dependent $\mathrm{Mg}^{2+}$ block by NMDA receptor may explain how strongly reduced glutamate release and reduced postsynaptic depolarization may still be sufficient to induce NMDA receptor-dependent LTP under high doses of fentanyl in the current study.

There are animal studies that show that acute tolerance can occur during anesthesia ${ }^{27}$ and even after a single dose of opioids. ${ }^{28}$ In a clinical trial, high doses of fentanyl led to higher postoperative pain intensity and greater fentanyl consumption. ${ }^{29}$ Whether the failure of high doses of fentanyl in our study to block LTP contributes to acute opioid tolerance remains to be determined. $^{28,30}$

It is important to note that at all doses that did not block LTP C fiber-evoked responses always remained below the control value. We can only speculate which level of $\mathrm{C}$ fiber-evoked potentials would be reached after the washout of fentanyl. Fentanyl accumulates as a result of its slow release by liver metabolism, and redistribution is less effective in removing fentanyl from its site of action, such as the central nervous system. Because the time course of complete washout of the lipophilic fentanyl in the rat spinal cord in vivo is not known but likely may last for many hours, it was not tested here.

Taken together, fentanyl in dosages with low analgesic potency completely blocks LTP but does not block LTP in higher doses.

The authors thank Magister Stephan Lehr (Institut für Medizinische Computerwissenschaften, Abteilung für Klinische Biometrie, Universität Wien, Wien, Austria) for his valuable help in preparing the statistical analysis

\section{References}

1. Crombie IK, Davies HT, Macrae WA: Cut and thrust: Antecedent surgery and trauma among patients attending a chronic pain clinic. Pain 1998; 76:167-71 
2. Reeh PW, Pethö G: Nociceptor excitation by thermal sensitization: A hypothesis, Nervous System Plasticity of Chronic Pain. Progress in Brain Research. Vol 219. Edited by Sandkühler J, Bromm B, Gebhart GF. Amsterdam, Elsevier, 2000, pp 39-50

3. Woolf CJ: Evidence for a central component of post injury pain hypersensitivity. Nature 1983; 306:686-8

4. Sandkühler J: Learning and memory in pain pathways. Pain 2000; 88:113-8

5. Sandkühler J, Benrath J, Brechtel C, Ruscheweyh R, Heinke B: Synaptic mechanisms of hyperalgesia, Nervous System Plasticity and Chronic Pain. Progress in Brain Research. Vol 129. Edited by Sandkühler J, Bromm B, Gebhart GF. Amsterdam, Elsevier, 2000, pp 81-100

6. Ikeda H, Heinke B, Ruscheweyh R, Sandkühler J: Synaptic plasticity in spinal lamina I projection neurons that mediate hyperalgesia. Science 2003; 299:1237-40

7. Schroeder JE, McCleskey EW: Inhibition of $\mathrm{Ca}^{2+}$ currents by a $\mu$-opioid in a defined subset of rat sensory neurons. J Neurosci 1993; 13:867-73

8. Ingram SL: Cellular and molecular mechanisms of opioid action. Progress in Brain Research. Vol 129. Edited by Sandkühler J, Bromm B, Gebhart GF. Amsterdam, Elsevier, 2000, pp 483-92

9. Mihic SJ, Ye Q, Wick MJ, Koltchine VV, Krasowski MD, Finn SE, Mascia MP, Valenzuela CF, Hanson KK, Greenblatt EP, Harris RA, Harrison NL: Sites of alcohol and volatile anaesthetic action on GABA(A) and glycine receptors. Nature 1997; 389:385-9

10. Simon W, Hapfelmeier G, Kochs E, Zieglgänsberger W, Rammes G: Isoflurane blocks synaptic plasticity in the mouse hippocampus. ANESTHESIOLOGY 2001; 94:1058-65

11. Vahle-Hinz C, Detsch O, Siemers M, Kochs E, Bromm B: Local GABA(A) receptor blockade reverses isoflurane's suppressive effects on thalamic neurons in vivo. Anesth Analg 2001; 92:1578-84

12. Antognini JF, Carstens E: Increasing isoflurane from 0.9 to 1.1 minimum alveolar concentration minimally affects dorsal horn cell responses to noxious stimulation. ANESTHESIOLOGY 1999; 90:208-14

13. Jevtovic-Todorovic V, Todorovic SM, Mennerick S, Powell S, Dikranian K, Benshoff N, Zorumski CF, Olney JW: Nitrous oxide (laughing gas) is an NMDA antagonist, neuroprotectant and neurotoxin. Nature Med 1998; 4:460-3

14. Liu X-G, Sandkühler J: Long-term potentiation of C-fiber-evoked potentials in the rat spinal dorsal horn is prevented by spinal N-methyl-D-aspartic acid receptor blockage. Neurosci Lett 1995; 191:43-6

15. Liu X-G, Sandkühler J: Activation of spinal N-methyl-D-aspartate or neuro- kinin receptors induces long-term potentiation of spinal C-fibre-evoked potentials. Neuroscience 1998; 86:1209-16

16. Hirota N, Kuraishi Y, Hino Y, Sato Y, Satoh M, Takagi H: Met-enkephalin and morphine but not dynorphin inhibit noxious stimuli induced release of substance P from rabbit dorsal horn in situ. Neuropharmacol 1985; 24:567-70

17. Aimone LD, Yaksh TL: Opioid modulation of capsaicin-evoked release of substance P from rat spinal cord in vivo. Peptides 1989;10: 1127-31

18. Kangrga I, Randic M: Outflow of endogenous aspartate and glutamate from the rat spinal dorsal horn in vitro by activation of low- and high-threshold primary afferent fibers: Modulation by $\mu$-opioids. Brain Res 1991; 553:347-52

19. Kumeta Y, Murata K, Kitahata LM, Aoki M, Nishio Y, Collins JG: Fentanyl suppression of nociceptive neurons in the superficial dorsal horn of the cat. ANESTHESIOLOGY 1988; 69:371-6

20. Serrao JM, Stubbs SC, Goodchild CS, Gent JP: Intrathecal midazolam and fentanyl in the rat: Evidence for different spinal antinociceptive effects. ANESTHESIOLOGY 1989; 70:780 - 6

21. Kozlowski CM, Bountra C, Grundy D: The effect of fentanyl, DNQX and MK-801 on dorsal horn neurones responsive to colorectal distension in the anaesthetized rat. Neurogastroenterol Motil 2000; 12:239-47

22. Terman GW, Eastman CL, Chavkin C: Mu opiates inhibit long-term potentiation induction in the spinal cord slice. J Neurophysiol 2001; 85:485-94

23. Mao J: NMDA and opioid receptors: Their interactions in antinociception, tolerance and neuroplasticity. Brain Res Reviews 1999; 30:289-304

24. Chen L, Huang L-YM: Sustained potentiation of NMDA receptor-mediated glutamate responses through activation of protein kinase $\mathrm{C}$ by a $\mu$ opioid. Neuron $1991 ; 7: 319-26$

25. Martin G, Nie Z, Siggins GR: $\mu$-Opioid receptors modulate NMDA receptormediated responses in nucleus accumbens neurons. J Neurosci 1997; 17:11-22

26. Chen L, Huang L-YM: Protein kinase $\mathrm{C}$ reduces $\mathrm{Mg}^{2+}$ block of MNDAreceptor channels as a mechanism of modulation. Nature 1992; 356:521-3

27. Askitopoulou H, Whitwam JG, Al-Khudhairi D, Chakrabarti M, Bower S, Hull CJ: Acute tolerance to fentanyl during anesthesia in dogs. Anesthesiology $1985 ; 63: 255-61$

28. Larcher A, Laulin JP, Celerier E, Le Moal M, Simonnet G: Acute tolerance associated with a single opiate administration: Involvement of N-methyl-D-aspartate-dependent pain facilitatory systems. Neuroscience 1998 ; 84:583-9

29. Chia YY, Liu K, Wang JJ, Kuo MC, Ho ST: Intraoperative high dose fentanyl induces postoperative fentanyl tolerance. Can J Anaesth 1999; 46:872-7

30. Fairbanks CA, Wilcox GL: Spinal plasticity of acute opioid tolerance. J Biomed Sci 2000; 7:200-12 